\title{
A Quick Approximation Method for Estimating the Dimensions of Patch Antennas using CMA
}

\author{
Bashar Bahaa Qas Elias, Ping Jack Soh and Azremi Abdullah Al-Hadi
}

\begin{abstract}
In this paper, a quick method for estimating the patch width is presented using CMA. The proposed method can be completed in four steps, based on the relationship between the patch width as the variable and different resonant frequencies, and has been validated using four substrates. This method is advantageous as it facilitates antenna designers in estimating the width of the radiator patch using only CMA without the effects of substrate and excitation. Basically, the generated formula enables the calculation of the actual patch width by simply substituting the width of the patch produced based on one of the CMA's characteristic angle. This parameter which is originally used to find the natural resonant frequency of the structure makes the proposed method time- and resource-efficient. The set of obtained results have been validated to be realistic with satisfactory accuracy.
\end{abstract} MoM.

\section{INTRODUCTION}

Characteristic mode analysis (CMA) been applied to understand the operating principles and use them to optimize the antenna's geometrical structure and performance [1]. The insight provided on the antenna radiating phenomenon makes it an efficient tool for designing antenna [2-3]. On the other hand, flexible textile antennas are gaining increasing attention due to their application in wearable systems [4-6]. Textile antennas are low-profile, thus is considered the best candidate to be integrated within clothing for wireless body area networks (WBANs) [7-8]. Due to the need for a planar configuration for wearable on-body antennas, patch antennas have been one of the most popular choices. For such antennas, their dimensions are critical in determining its operating frequency and final performance. Different methods based on classical formulas (and calculators derived from them) are available to estimate a set of initial dimensions. They can be summarized as follows:

- the transmission-line model (TL) formula which can be used to design conventional patch antennas is explained in [9-10]. This method assumes that the patch antenna is designed with known operating frequency, dielectric constant, and substrate thickness.

All authors are with the Advanced Communication Engineering (ACE) CoE, Faculty of Electronic Engineering Technology, Universiti Malaysia Perlis (UniMAP), Pauh Putra Campus, Arau 02600, Perlis, Malaysia. B.B.Q. E. is also with the Department of Communication Engineering Techniques, Imam Ja'afar Al-sadiq University, Baghdad 10052, Iraq (e-mail: bashar.bahaa@sadiq.edu.iq). P.J.S. is now with the Centre for Wireless Communications, University of Oulu, Finland.
- the concept of equivalent design [11-12]. In this method, the dimensions of a rectangular patch antenna is estimated repetitively when designs are made for the same frequency but for different dielectric constants.

- the artificial neural network model (ANN) method is used to estimate the dimensions (length, width) of a rectangular patch antenna. Input parameters include substrate thickness and dielectric constant, resulting in a minimum level of percentage of error was reported in [13].

- the particle swarm optimization technique is used for the precise calculation of the parameters of a rectangular patch antenna. This resulted in resonant frequency and feed point of the antenna with any dimensions and any substrate thickness [14].

This work proposes a method to introduce specific formula for each substrate in sequential steps, based on the simulation results from CMA and method of moment (MoM). These formulas are then used to quickly estimate the patch dimensions when operating at different frequencies based only on the CMA. The proposed relations between the two methods bridges the changes of the natural resonant frequencies contributed by the properties of any substrate materials, and by extension, on its dimensions. Due to this, designers are able to use the end 'calibrated' results to generate specific formulas for each antenna to simply calculate the width of the patch at different operating frequencies. The next section presents the data collection, followed by the generation of formula. Finally, section 3 concludes the proposed work.

\section{THE APPROXIMATE MATHEMATICAL ForMUlA}

\section{A. Data Collection}

The first step in the proposed method is to calculate the patch's width and length based on CMA without including the substrate and excitation. This is followed by the calculation of the patch width and length using MoM, including the substrate and excitation. The collected CMA data can be either the modal significance (MS), characteristic angles (CA), or eigenvalues. MS represents the normalized amplitude of the current modes. A mode is considered at resonance when its modal significance is closer to unity or at least 0.7. Also, CA gives an understanding of the mode behavior near resonance. In this study, CA is chosen as the CMA parameter, as shown in Fig. 1. It is easier to use the CA to investigate the resonance of a structure than the MS parameter. Mode 1 can be observed as a dominant mode, and it becomes more efficient at a specific operating frequency as 
the $\mathrm{CA}$ moves closer to $180^{\circ}$. The patch dimension at $\mathrm{CA}=$ $180^{\circ}$ is then recorded in Tables I to VIII. The previous process is repeated next using MoM, aimed at achieving a minimum reflection coefficient at the operating frequency. The patches dimensions obtained at this step are also recorded. All steps are performed for consecutive frequencies using FEKO software, where simulation is performed for each dimension. Four substrates are used to validate the suggested method, as follows:

1. Felt (with a relative permittivity of $\varepsilon_{\mathrm{r}}=1.3$, loss tangent $(\tan \delta)=0.044$, and thickness $=3 \mathrm{~mm})$.

2. RO4003C substrate $\left(\varepsilon_{\mathrm{r}}=3.4\right.$, $\tan \delta=0.002$, and thickness $=0.085 \mathrm{~mm})$.

3. Jeans fabric $\left(\varepsilon_{\mathrm{r}}=1.7, \tan \delta=0.085\right.$, and thickness $=1$ $\mathrm{mm})$.

4. Rogers RT/Duroid 5880 substrate $\left(\varepsilon_{\mathrm{r}}=2.2\right.$, $\tan \delta=$ 0.0009 , and thickness $=0.508 \mathrm{~mm}$ )

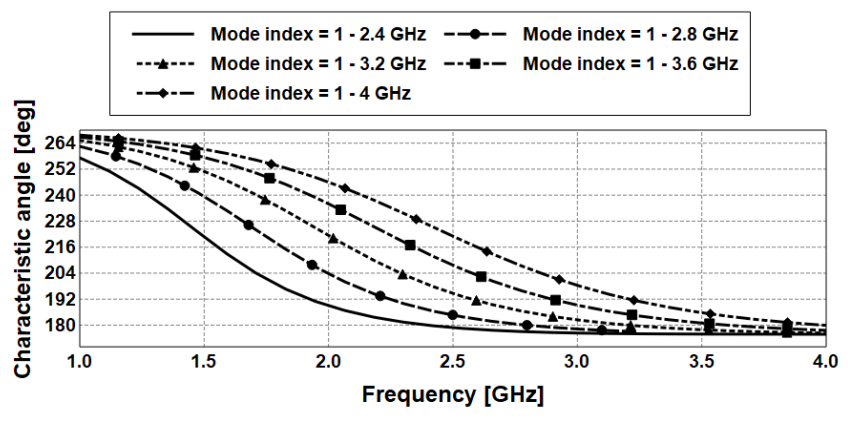

Fig. 1. Characteristic angle of a square patch at different operating frequencies.

The formula proposed for each substrate facilitates the estimation of the patch dimensions without the effects of the substrate, ground, and excitation. In turn, this process makes the overall design process more time efficient. Besides being not limited to traditional patches, this method can also be used to estimate the dimensions for the patch with multiple slots if the dominant modes are correctly excited. The patch dimensions from each substrate type are presented in Tables I to IV. A systematic procedure of the proposed method is summarized in Fig. 2.

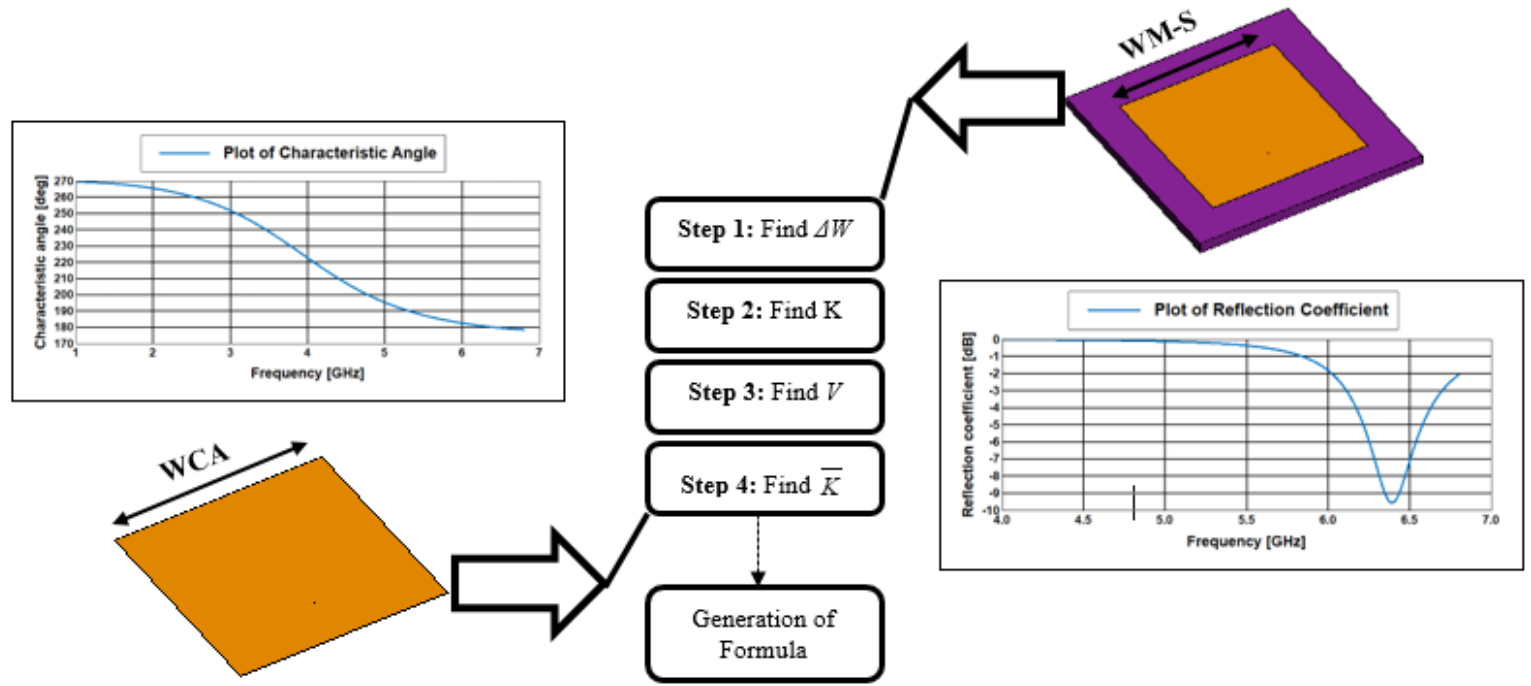

Fig. 2. Summarized the process of generation formula.

TABLE I

PATCH WIDTH ESTIMATION ON FELT SUBSTRATE USING CMA

\begin{tabular}{|c|c|c|c|c|c|c|}
\hline$f(\mathrm{GHz})$ & $\begin{array}{l}W C A \\
(\mathrm{~mm})\end{array}$ & $\begin{array}{l}W M-S \\
(\mathrm{~mm})\end{array}$ & $\Delta W=W C A-W M-S(\mathrm{~mm})$ & $K=W M-S / \Delta W$ & $\begin{array}{l}W M-F \\
(\mathrm{~mm})\end{array}$ & $D=|W M-S-W M-F|(\mathrm{mm})$ \\
\hline 2.4 & 70 & 48.7 & 21.3 & 2.28 & 48.4 & 0.3 \\
\hline 2.6 & 64.7 & 44.71 & 19.99 & 2.23 & 44.69 & 0.02 \\
\hline 2.8 & 60 & 41.5 & 18.5 & 2.24 & 41.4 & 0.1 \\
\hline 3.0 & 56 & 38.62 & 17.38 & 2.22 & 38.6 & 0.02 \\
\hline 3.2 & 52.3 & 36.04 & 16.26 & 2.21 & 36.01 & 0.03 \\
\hline 3.4 & 49.3 & 33.91 & 15.39 & 2.2 & 33.91 & 0 \\
\hline 3.6 & 46.5 & 31.96 & 14.54 & 2.19 & 31.95 & 0.01 \\
\hline 3.8 & 44.1 & 30.26 & 13.84 & 2.18 & 30.27 & 0.01 \\
\hline 4.0 & 42 & 28.8 & 13.2 & 2.18 & 28.8 & 0 \\
\hline
\end{tabular}


TABLE II

PATCH WIDTH ESTIMATION ON A RO4003C SUBSTRTAE USING CMA

\begin{tabular}{ccccccc}
\hline \hline$f(\mathrm{GHz})$ & $\begin{array}{c}W C A \\
(\mathrm{~mm})\end{array}$ & $\begin{array}{c}W M-S \\
(\mathrm{~mm})\end{array}$ & $\Delta W=W C A-W M-S(\mathrm{~mm})$ & $K=W M-S / \Delta W$ & $\begin{array}{c}W M-F \\
(\mathrm{~mm})\end{array}$ & $D=|W M-S-W M-F|(\mathrm{mm})$ \\
\hline 2.4 & 70 & $\mathbf{3 4 . 5}$ & 35.5 & 0.97 & $\mathbf{3 4 . 7}$ & 0.2 \\
2.6 & 64.7 & $\mathbf{3 1 . 8 9}$ & 32.81 & 0.97 & $\mathbf{3 1 . 9 4}$ & 0.05 \\
2.8 & 60 & $\mathbf{2 9 . 3}$ & 30.7 & 0.95 & 0.95 & $\mathbf{2 9 . 5}$ \\
3.0 & 56 & $\mathbf{2 7 . 4}$ & 28.6 & 0.94 & $\mathbf{2 5 . 4 2}$ & 0.02 \\
3.2 & 52.3 & $\mathbf{2 5 . 4 7}$ & 26.83 & 0.93 & $\mathbf{2 3 . 9 3}$ & 0.05 \\
3.4 & 49.3 & $\mathbf{2 3 . 8 8}$ & 25.42 & 0.92 & $\mathbf{2 2 . 4 8}$ & 0.08 \\
3.6 & 46.5 & $\mathbf{2 2 . 4}$ & 24.1 & 0.91 & $\mathbf{2 1 . 2 3}$ & 0.13 \\
3.8 & 44.1 & $\mathbf{2 1 . 1}$ & 23 & 0.91 & $\mathbf{2 0 . 1 4}$ \\
4.0 & 42 & $\mathbf{2 0 . 0 3}$ & 21.97 & & & 0.11 \\
\hline \hline
\end{tabular}

TABLE III

PATCH WIDTH ESTIMATION ON JEANS FABRIC USING CMA

\begin{tabular}{ccccccc}
\hline \hline$f(\mathrm{GHz})$ & $\begin{array}{c}W C A \\
(\mathrm{~mm})\end{array}$ & $\begin{array}{c}W M-S \\
(\mathrm{~mm})\end{array}$ & $\Delta W=W C A-W M-S(\mathrm{~mm})$ & $K=W M-S / \Delta W$ & $\begin{array}{c}W M-F \\
(\mathrm{~mm})\end{array}$ & $D=|W M-S-W M-F|(\mathrm{mm})$ \\
\hline 2.4 & 70 & $\mathbf{4 4 . 7 5}$ & 25.25 & 1.77 & $\mathbf{4 4 . 6 5}$ & 0.1 \\
2.6 & 64.7 & $\mathbf{4 1 . 3}$ & 23.4 & 21.8 & 1.76 & $\mathbf{4 1 . 2 0 5}$ \\
2.8 & 60 & $\mathbf{3 8 . 2}$ & 20.43 & 1.75 & $\mathbf{3 8 . 1 5}$ & 0.095 \\
3.0 & 56 & $\mathbf{3 5 . 5 7}$ & 19.1 & 1.74 & $\mathbf{3 5 . 5 5}$ & 0.05 \\
3.2 & 52.3 & $\mathbf{3 3 . 2}$ & 18.08 & 1.73 & $\mathbf{3 3 . 1 4 3}$ & 0.055 \\
3.4 & 49.3 & $\mathbf{3 1 . 2 2}$ & 17.1 & 1.71 & $\mathbf{3 1 . 1 9 5}$ & $\mathbf{2 9 . 3 7 5}$ \\
3.6 & 46.5 & $\mathbf{2 9 . 4}$ & 16.28 & 1.7 & $\mathbf{2 7 . 8 1 5}$ & 0.025 \\
3.8 & 44.1 & $\mathbf{2 7 . 8 2}$ & 15.5 & 1.7 & $\mathbf{2 6 . 4 5}$ \\
4.0 & 42 & $\mathbf{2 6 . 5}$ & & & 0.025 \\
\hline \hline
\end{tabular}

TABLE IV

PATCH WIDTH ESTIMATION ON ROGERS RT/Duroid 5880 SUBSTRATE USING CMA

\begin{tabular}{ccccccc}
\hline \hline$f(\mathrm{GHz})$ & $\begin{array}{c}W C A \\
(\mathrm{~mm})\end{array}$ & $\begin{array}{c}W M-S \\
(\mathrm{~mm})\end{array}$ & $\Delta W=W C A-W M-S(\mathrm{~mm})$ & $K=W M-S / \Delta W$ & $\begin{array}{c}W M-F \\
(\mathrm{~mm})\end{array}$ & $D=|W M-S-W M-F|(\mathrm{mm})$ \\
\hline 2.4 & 70 & $\mathbf{4 1 . 6}$ & 28.4 & 1.46 & 0 & $\mathbf{4 1 . 6}$ \\
2.6 & 64.7 & $\mathbf{3 8 . 3 5}$ & 26.35 & 1.45 & $\mathbf{3 8 . 3 6 7}$ & 0.017 \\
2.8 & 60 & $\mathbf{3 5 . 4 8}$ & 24.52 & 1.44 & 1.43 & $\mathbf{3 5 . 5}$ \\
3.0 & 56 & $\mathbf{3 3}$ & 23 & 1.43 & $\mathbf{3 3 . 0 6}$ & 0.02 \\
3.2 & 52.3 & $\mathbf{3 0 . 8}$ & 21.5 & 1.42 & $\mathbf{2 8 . 9 7 3}$ & 0.003 \\
3.4 & 49.3 & $\mathbf{2 8 . 9 7}$ & 19.235 & 1.41 & $\mathbf{2 7 . 2 6 5}$ & 0.003 \\
3.6 & 46.5 & $\mathbf{2 7 . 2 6 5}$ & 18.3 & 1.4 & $\mathbf{2 5 . 8 0 1}$ & 0 \\
3.8 & 44.1 & $\mathbf{2 5 . 8}$ & 17.49 & 1.4 & $\mathbf{2 4 . 5 2}$ \\
4.0 & 42 & $\mathbf{2 4 . 5 1}$ & & & 0.001 \\
\hline \hline
\end{tabular}

\section{B. Generation of Formula}

The formulas to perform these estimations are derived as follows.

$$
\Delta W=W_{C A}-W_{M-S}
$$

where $W_{C A}$ is the width of the patch calculated using the CMA method without substrate and excitation, and $W_{M-S}$ is the width of the patch calculated using MoM (with substrate and excitation). Then, the ratio between the patch width produced by a full-wave analysis to the difference between the width values produced by CMA and full-wave analysis, $K$ can be calculated as:

$$
K \approx \text { Average }\left[W_{M-S} / \Delta W\right]
$$

Next, the general form of the proposed formula, $W_{M-F}$ is calculated as:

$$
W_{M-F}=\left[K W_{C A} / \bar{K}\right]-V
$$

where $V=\varepsilon_{r} / 2$ represents the value of substrate permittivity divided by 2 , and $\bar{K}$ represents the value of $k$ with an estimated correction factor $(R)$ which varies between $(0.8$ to $0.9)$ for all substrates, calculated as:

$$
\bar{K}=K+R
$$

Finally, the deviation between the patch width value in simulation and the proposed formula, $D$, is used to determine the accuracy of the proposed method, as follows:

$$
D=W_{M-S}-W_{M-F}
$$

The final step is to collect all data and use them to estimate a set of customized formula for each substrate, as presented in Table V. These simple closed-form formulas provide satisfactory accuracy in estimating the patch dimensions. As shown in Fig. 3, the rate of the deviations in dimension between the values obtained from the formula and the actual value varies depending on the operating frequencies. It can be 
seen that the value of the deviation is relatively higher at some of the operating frequencies due to the effect of dielectric constant, thicknesses, and dimensions of the substrate used. However, their variations are less than $0.5 \mathrm{~mm}$, which indicates the accuracy of the proposed formula in estimating the patch dimensions.

TABLE V

PROPOSED FORMULAS FOR DIFFERENT SUBSTRATE MATERIALS

\begin{tabular}{lllll}
\hline \hline Substrate & $\begin{array}{l}\text { Dielectric } \\
\text { constant } \\
\left(\varepsilon_{\mathrm{r}}\right)\end{array}$ & $\begin{array}{l}\text { Loss } \\
\text { tangent } \\
(\tan \delta)\end{array}$ & $\begin{array}{l}\text { Thickness } \\
(\mathrm{mm})\end{array}$ & $\begin{array}{l}\text { Proposed } \\
\text { formula }\end{array}$ \\
\hline Felt & 1.3 & 0.044 & 3 & $\begin{array}{l}\text { WM-F } \\
(0.7 \mathrm{WCA})-0.6\end{array}$ \\
RO4003C & 3.4 & 0.002 & 0.085 & $\begin{array}{l}\text { WM-F } \\
(0.52 \mathrm{WCA})-1.7\end{array}$ \\
Fabric & 1.7 & 0.085 & 1 & $\begin{array}{l}\text { WM-F } \\
(0.65 \mathrm{WCA})-\end{array}$ \\
$\begin{array}{l}\text { Jeans } \\
\text { Rogers } \\
\text { RT/Duroid } \\
5880\end{array}$ & 2.2 & 0.0009 & 0.508 & $\begin{array}{l}\text { WM-F } \\
(0.61 \mathrm{WCA})-1.1\end{array}$ \\
\hline \hline
\end{tabular}

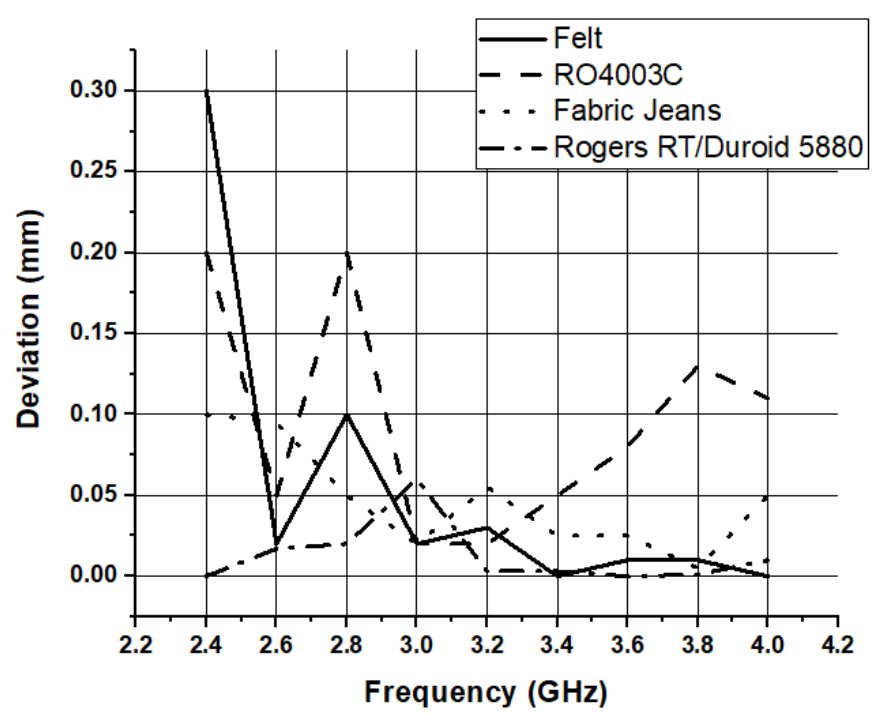

Fig. 3. Deviation results at different substrates

\section{CONCLUSIONS}

In this paper, a new procedure based on the CMA technique to quickly estimate the dimensions of the patch on different substrate materials is presented. Four steps are proposed to create the formula by finding a relationship between the variable data obtained at different resonant frequencies. This enables the quick estimation of the dimensions of the patch using CMA without including the substrate and excitation.

\section{ACKNOWLEDGMENT}

This work was supported in part by the Academy of Finland 6Genesis Flagship under grant no. 318927.

\section{REFERENCES}

[1] J. Dong and S. Wang, "Design of a twelve-port MIMO antenna system for multi-mode $4 \mathrm{G} / 5 \mathrm{G}$ smartphone applications based on characteristic mode analysis", IEEE Access, 2020; 8, pp. 90751 - 90759, doi: 10.1109/ACCESS.2020.2994068.

[2] Y. Luo, Z.N. Chen and K. Ma, "A single-layer dual-polarized differentially fed patch antenna with enhanced gain and bandwidth operating at dual compressed high-order modes using characteristic mode analysis," IEEE Transactions on Antennas and Propagation, 2020; 68(5), pp. 4082 - 4087, doi: 10.1109/TAP.2019.2951536.

[3] J.E. Bauer and P.K. Gentner, "Characteristic mode analysis of a circular polarised rectangular patch antenna", 13th European Conference on Antennas and Propagation (EuCAP), 2019.

[4] R. Aprilliyani, P.A. Dzagbletey, J.H. Lee, M.J. Jang, J-H. So and J-Y Chung, "Effects of textile weaving and finishing processes on textilebased wearable patch antennas", IEEE Access, 2020, 8, pp. 63295 63301, doi: 10.1109/ACCESS.2020.2984934.

[5] K. Pulanthran, N.M. Jizat and M.S. Islam, "A low-cost textile antenna using thermal-transfer printing", 16th IEEE International Colloquium on Signal Processing \& Its Applications (CSPA), 2020, doi: 10.1109/CSPA48992.2020.9068726.

[6] S. Sekkal, L. Canale and A. Asselman, "Flexible textile antenna design with transparent conductive fabric integrated in OLED for WiMAX wireless communication systems", IEEE International Conference on Environment and Electrical Engineering and 2020 IEEE Industrial and Commercial Power Systems Europe (EEEIC / I\&CPS Europe), 2020, doi: 10.1109/EEEIC/ICPSEurope49358.2020.9160757.

[7] D. Yamanaka and M. Takahashi, "Design of a dual-band dualpolarization method for a textile antenna", International Workshop on Antenna Technology (iWAT), 2020, doi: 10.1109/iWAT48004.2020.1570598503.

[8] B.B. Qas Elias, P.J. Soh, A.A. Al-Hadi, R. Joshi, Y. Li and S.K. Podilchak, "Design of a quad band CPW-fed compact flexible patch antenna for wearable applications", 14th European Conference on Antennas and Propagation (EuCAP), 2020, doi: 10.23919/EuCAP48036.2020.9135261.

[9] R. Garg, "Microstrip antenna design handbook", Reading, MA: Artech House, Boston, 2011.

[10] A.B. Constantine, "Antenna theory: analysis and design", Third Edition, John Wiley \& Sons, Inc., Publication, New Jersey.

[11] D. Mathur, S.K. Bhatnagar and V. Sahula V, "Quick estimation of rectangular patch antenna dimensions based on equivalent design concept", IEEE Antennas and Wireless Propagation Letters, 2014, 13, pp. 1469 - 1472, doi: 10.1109/LAWP.2014.2334362.

[12] M. Mathur, A. Vats and A. Agarwal, "A new design formulae for feed line dimensions of the rectangular microstrip patch antenna by using equivalent design concept", International Conference on Signal Processing and Communication (ICSC), 2015, doi: 10.1109/ICSPCom.2015.7150629.

[13] A. Kaur and R. Mittal, "Dimensions estimation of wide band rectangular microstrip patch antenna based on artificial neural network ,"Second International Conference on Intelligent Computing and Control Systems (ICICCS), 2018, doi: 10.1109/ICCONS.2018.8662975.

[14] V.S. Chintakindi, S.S. Pattnaik, O.P. Bajpai, S. Devi, S.V.R.S Gollapudi and P.K. Pradyumna, "Parameters calculations of rectangular microstrip patch antenna using particle swarm optimization technique", IEEE Applied Electromagnetics Conference (AEMC), 2007, doi: 10.1109/AEMC.2007.4638010. 